\title{
Changes of the toxic potential of drinking water containing aminopyrine before and after chlorine disinfection as determined by the algal toxicity assay and the SOS/umu assay
}

\author{
Ai-jie Jin ${ }^{\text {a }}$ Li Feng ${ }^{\text {a }}$, Li-qiu Zhang ${ }^{\text {a,* }}{ }^{\text {, Yong-ze Liu }}{ }^{\text {a }}$

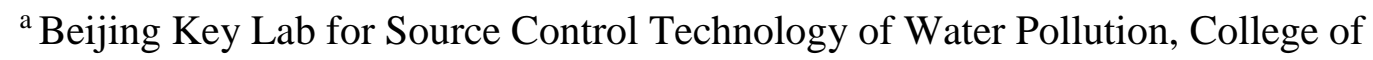 \\ Environmental Science and Engineering, Beijing Forestry University, Beijing 100083, China. \\ ${ }^{*}$ Corresponding author. Tel.: +86 010 63226528; Fax: 86-010-62336900. E-mail addresses: \\ zhangliqiu@163.com_(L.-Q. Zhang).
}

\begin{abstract}
This paper investigated the potential eco-toxicity changes of the drinking water containing aminopyrine (AMP) before and after chlorination. For the determination of the acute toxicity and genotoxicity, algal toxicity assay and SOS/umu assay were adopted respectively. In these toxicity assays, the AMP exposure group was compared with the control group or the chlorination group to illustrate the changes. Results showed that the algal growth inhibition percentage increased with the increase of AMP concentration. After AMP chlorination, the inhibition percentage decreased at relatively low chlorine ratios (ie, the AMP to chlorine molar ratio of $4: 1$ and 1:1) but increased at high chlorine ratios (ie, the AMP to chlorine molar ratio of $1: 2$ and 1:5). The superoxide dismutase (SOD) avtivity was stimulated at AMP to chlorine molar ratios of 4:1 while inhibited at 1:5. The change of malondialdehyde (MDA) content was just opposite to the SOD activity. In SOS/umu assay, when the molar ratios of AMP and chlorine were 1:1, 1:2 and 1:5, the values of induction ratio (IR) were over 1.5 and showed a positive genotoxicity signal in the absence/presence of S9 homogenate.

Further, the Toxic Equivalent Quantity (TEQ) value, which was used to express the genotoxic potentials of those positive samples, gradually increased with the increase of chlorine ratio. In a word, the potential genotoxicity of chlorinated drinking water containing AMP should be of a concern.
\end{abstract}

KEYWORDS: Acute toxicity; Genotoxicity; SOS/umu assay; Chlorination; Aminopyrine 


\section{INTRODUCTION}

In recent years, pharmaceuticals and personal care products (PPCPs) in the aquatic environment have received growing concerns as emerging contaminants for their worldwide occurrence and permanent presence. PPCPs include more than 3000 different substances used as medicines ranging from analgesics and antibiotics to lipid regulators and veterinary medicine (Ternes et al., 2004), in addition to the active ingredients in detergents, perfumes, and hair, skin, and dental care products (Liu and Wong, 2013). Among the large number of different organic compounds, pharmaceutical compounds together with their metabolites and transformation products have been detected in the effluent of sewage treatment plants, surface water and groundwater (Daughton and Ternes, 1999; Greskowiak et al., 2006; Quintana et al., 2007), and many of them can further spread through water cycle, even reach drinking water (Reddersen et al., 2002). This fact has resulted in the emergence of concerns about the safety of drinking water.

Aminopyrine (AMP, also known as aminophenazon) is an analgesic and anti-inflammatory drug. On account of its detrimental impacts on human liver and other target organs, AMP was banned in the 1970s in some western countries. However, it is still used in other areas due to its low-cost and high effectiveness. Unfortunately, the AMP removal efficiency within conventional wastewater treatment facilities was only approximately $38 \%$ (Jeličić and Ahel, 2003; Ternes, 1998), which means sizable part of AMP may enter the natural aquatic environment. A survey about the occurrence of AMP has found that it is the frequently detected compound from the raw water in drinking water treatment plants, Beijing (Cai et al., 2015). And these pharmaceutical residues were also found in raw water from all Berlin water works (Heberer et al., 2002). Generally, conventional processes in drinking water treatment (coagulation/flocculation, sedimentation, filtration) are unable to remove AMP effectively so that considerable attention to the chemical disinfection unit has been paid. Up to now, chlorination is the main chemical disinfection measure applied worldwide due to its low cost. Although free chlorine can remove AMP quickly and effectively, chlorination process could not mineralize it completely and some highly toxic by-products might be produced inevitably (Cai et al., 2014). To the best of our knowledge, the majority of studies were mainly focused on the occurrence, fate and removal of AMP (Heberer et al., 2002; Heberer et al., 2011), there is still a real lack of information on the environmental risk 
characterization, especially about data for eco-toxicity during AMP chlorination. Consequently, particular attention should be paid to the acute toxicity and genotoxicity of drinking water containing AMP during chlorination.

At present, several guidelines for the determination of the acute toxicity (GB/T15441, 1995; Oecd, 1994) and genotoxicity (Guideline, 2011; Kirkland et al., 2005) have been published. Some previous studies found that bacterium, crustacean, fish or daphnia were not as sensitive as alga during short-term exposures (Brausch and Rand, 2011; Cleuvers, 2003; Sanderson et al., 2003). The Chlorella vulgaris (C. vulgaris) is widely employed in toxicity tests as a kind of green algal species. Accordingly, the $C$. vulgaris was chosen for the algal toxicity assay in this study. Genotoxicity is significant in toxicological studies because DNA damage can trigger a sequence of biological consequences at the cellular, organ, whole organism, even population and community levels. The SOS/umu assay is one of the short-term and micro-scale genotoxicity tests for detecting DNA damage. The system is based on the ability of DNA damaging agents to induce the expression of the $u m u C$-gene, and the итиC-gene is essentially involved in bacterial mutagenesis via the so-called SOS-pathway (Reifferscheid and Heil, 1996). This test has been widely used for screening genotoxic compounds and for evaluating the genotoxicity of water and waste water (Žegura et al., 2009).

In the present study, AMP exposure group, chlorination group and control group were conducted. A gradient of AMP concentration was set up in AMP exposure group. In chlorination group, the AMP chlorination was at different molar ratios of AMP and chlorine $\left(\mathrm{Cl}_{2}\right)(4: 1,1: 1,1: 2,1: 5)$. The objective of this study was to evaluate the acute toxicity and the genotoxic potential in chlorination group compared with AMP exposure group and control group. The acute toxicity was evaluated on the growth and enzyme activities variation of the C. vulgaris. Moreover, the SOS/umu test was conducted to explore the genotoxicity of AMP during chlorination on Salmonella typhimurium TA1535/pSK1002.

\section{MATERIALS AND METHODS}

\subsection{Reagents and materials}

AMP with > 99\% purity was purchased from Sigma-Aldrich (USA). A stock solution of AMP ( 0.04 mmol mL $\left.\mathrm{mL}^{-1}\right)$ was prepared with ultra-pure water as necessary after dissolution with $1 \mathrm{~mL}$ methanol (Fisher Scientific) and then protected from light and stored at $4{ }^{\circ} \mathrm{C}$ prior to using. The concentration of methanol during each experiment had no impact on the 
oxidation of AMP (Dodd et al., 2005) and no toxicity on the testing organisms (de Melo et al., 2013). Sodium hypochlorite solution $(\mathrm{NaClO})$ with $\sim 13 \%$ available chlorine was purchased from Sigma-Aldrich. Its stock solutions at the desired level $\left(\sim 1.41 \mathrm{mmol} \mathrm{L}^{-1}, \mathrm{Cl}_{2}\right)$ were prepared daily by dilution in ultra-pure water and their concentration was quantified using the DPD (N, N-diethyl-p-phenylenediamine) colorimetric method with photometric detection (Federation and Association, 2005). Ultra-pure water $(18 \mathrm{M} \Omega \cdot \mathrm{cm})$ obtained in the lab from a Water Purification System (ELGA Purelab Classic, Veolia) was used to prepare all the reagent solutions.

\subsection{Algal toxicity assay}

\subsubsection{Cultivation of the C. vulgaris}

The C. vulgaris was purchased from Beijing Municipal Research Institute of Environmental Protection. It was pre-cultivated in $500 \mathrm{~mL}$ Erlenmeyer flasks containing 125 $\mathrm{mL}$ sterile M11 medium (Elkonin and Pakhomova, 2000) at $23 \pm 1{ }^{\circ} \mathrm{C}$ under a $12 \mathrm{~h} \mathrm{light/dark}$ cycle illumination (40001x, RXZ-380B) for two weeks. In order to reduce any effect caused by the accidental error from orientation, the flasks were shaken manually over three times each day and rearranged randomly. After pre-cultivation, the $C$. vulgaris could be used for the toxicity assays during its exponential growth phase.

\subsubsection{Preparation of the test samples}

In order to investigate the acute toxicity and genotoxicity of AMP before and after chlorination, test samples are grouped as follows: AMP exposure group, chlorination group and control group. AMP exposure group was conducted to investigate the potential toxicity of AMP. In this group, the $C$. vulgaris in exponential growth phase was exposed to different AMP concentrations $\left(0.009,0.017,0.035,0.069,0.138 \mathrm{mmol} \mathrm{L}^{-1}\right)$. The chlorination group was carried out to investigate the variation of the acute toxicity after AMP chlorination. A series of amber borosilicate bottles with glass stoppers $(500 \mathrm{ml})$ were used as reactors. AMP at different concentrations $\left(0.009,0.017,0.035,0.069,0.138 \mathrm{mmol} \mathrm{L}^{-1}\right)$ was spiked into the above bottles, and then corresponding $\mathrm{NaClO}$ solutions were added into each bottle according to different molar concentration ratios of AMP : chlorine $\left(\mathrm{Cl}_{2}\right)(4: 1,1: 1,1: 2$ and 1:5). The reaction was carried out for $20 \mathrm{~h}$ with continuous magnetic stirring at $24 \pm 0.5^{\circ} \mathrm{C}$. Then, each 
test sample was purged with nitrogen up to ten minutes to remove the residual chlorine until it was under the limit of detection $\left(<0.004 \mathrm{mg} \mathrm{L}^{-1}\right)$. Residual chlorine was determined by using the DPD Standard Method. After that, the AMP chlorination solutions were added into the $C$. vulgaris culture to investigate their impact on the algal growth and enzyme activities. In the control group, the $C$. vulgaris in exponential growth phase was cultivated with neither AMP exposure nor AMP chlorination. In this way, the growth and enzyme activities of the $C$. vulgaris without AMP or chlorination can be observed. All treatments were in triplicate under similar incubation conditions and the average data were presented.

\subsubsection{Algal growth inhibition test}

Algal growth inhibition test was performed in accordance with the Organization for Economic Co-operation and Development (OECD) Guidelines for the Testing of Chemical (Oecd, 1994) under axenic conditions. The test duration was 3 day. Before the test, cells of the C. vulgaris in exponential growth phase were counted using a haemacytometer under a microscope (Olympus CX41, Japan). Meanwhile, the optical density at $680 \mathrm{~nm}\left(\mathrm{OD}_{680}\right)$ was determined using an Evolution $300 \mathrm{UV}$-Vis spectrophotometer (Thermo, USA). The linear relationship between cell density and optical density was built up with the relevant index $\mathrm{R}^{2}>$ 0.99, which showed a good accordance with the previous report (Ge et al., 2010). During this test, triplicate samples from three test groups mentioned above were collected at intervals of 1 day over a period of 3 days exposure, and their $\mathrm{OD}_{680}$ was determined. The average specific growth rate of the $C$. vulgaris $(\mu)$ and the inhibition percentage of the growth of the $C$. vulgaris (I) were calculated according to Eq. (1) and (2), respectively:

$$
\begin{aligned}
& \mu=\frac{\ln X_{n}-\ln X_{0}}{t} \\
& I=\frac{\mu_{0}-\mu}{\mu_{0}} \times 100 \%
\end{aligned}
$$

where $X_{n}$ is the cell density of the $C$. vulgaris after $n(n=1,2,3)$ day exposure, $X_{0}$ is the cell density of the $C$. vulgaris at the beginning of the toxicity test, $t$ is the period of exposure (day), and $\mu_{0}$ is the mean growth rate of the control group.

\subsubsection{Determination of the enzyme activities}

After 4 days exposure, cells of the C. vulgaris from the AMP exposure group, chlorination group and the control group were harvested by centrifuged at $5,000 \mathrm{rpm}\left(4{ }^{\circ} \mathrm{C}\right)$ 
for $15 \mathrm{~min}$. After that, the harvested cells were suspended in $0.1 \mathrm{M}$ phosphate buffer saline (pH 7.4) and then crushed by an ultrasonic cell crusher (JY92- II N, China) at $200 \mathrm{~W}$ (ultrasonic/rest $=5: 5 \mathrm{~s}$ ) in an ice bath for $5 \mathrm{~min}$. Then, the homogenate was centrifuged at $10,000 \mathrm{rpm}$ for $10 \mathrm{~min}$ at $4{ }^{\circ} \mathrm{C}$. At last, the supernatant was used to measure the enzyme activities of superoxide dismutase (SOD) and the content of malondialdehyde (MDA). All the analyses were determined following the reagent kit's Operation Manual from Nanjing Jiancheng Bioengineering Institute (China).

\subsection{SOS/umu assay}

In the preliminary preparation of the test samples, in order to have a convincing result, AMP at a relatively high concentration $\left(0.138 \mathrm{mmol} \mathrm{L}^{-1}\right)$ and its corresponding chlorination treatment samples at different molar ratios of AMP and chlorine (4:1, 1:1, 1:2 and 1:5) were prepared (the method was the same as 2.2.2). A series of $500 \mathrm{~mL}$ amber borosilicate bottles with glass stoppers were set up and each bottle was filled with $500 \mathrm{~mL}$ test samples. To concentrate these test samples, each of them was extracted by the solid-phase extraction (SPE) equipment (Mediwax 12-ports Vacuum SPE manifold) at a speed of $3 \mathrm{~mL} \mathrm{~min}^{-1}$. Oasis HLB cartridges $(500 \mathrm{mg}, 6 \mathrm{~mL}$, Waters, USA) were preconditioned with $1 \times 5 \mathrm{~mL}$ dichloromethane, $1 \times 5 \mathrm{~mL}$ methanol and $1 \times 5 \mathrm{~mL}$ ultrapure water (flow rate $\leq 1 \mathrm{~mL} \mathrm{~min}^{-1}$ ). After loading samples and washing with $1 \times 5 \mathrm{~mL}$ ultrapure water, the cartridges were eluted with $1 \times 9 \mathrm{~mL}$ dichloromethane and $1 \mathrm{~mL}$ methanol. Subsequently, the eluents were nearly reduced to dryness by sample concentrator (HN132, Hanon Instruments) under a continuous gentle stream of nitrogen and then redissolved with dimethyl sulfoxide (DMSO, Sigma-Aldrich) to the ultimate volumes of $100 \mu \mathrm{L}$. The final extracts were stored at $-20{ }^{\circ} \mathrm{C}$ prior to genotoxicity assay.

The genotoxicity of test samples on Salmonella typhimurium TA1535/pSK1002 was tested by the SOS/umu assay with and without S9 rat liver homogenate (Oriental Yeast, Tokyo) activation according to ISO 13829 standard (ISO13829, 2002) with some modifications from Y. Oda et al (Oda et al., 1985). The strain was provided by the Osaka Prefectural Institute of Public Health, Japan. It was pre-cultured in Luria-Bertani (L-B) broth medium in an incubator at $37{ }^{\circ} \mathrm{C}, 175 \mathrm{rpm}$ for $2 \mathrm{~h}$. For determination of the direct DNA-damaging effect (direct genotoxicity), $198 \mu \mathrm{L}$ of exponentially growing bacterial and $2 \mu \mathrm{l}$ of test sample were well-distributed in each well of a 96-well microplate (Corning). For determination of the indirect DNA-damaging effect (indirect genotoxicity), $198 \mu \mathrm{L}$ of exponentially growing 
bacteria mixed with S9 mixture (4.8:1) was exposed to $2 \mu \mathrm{L}$ of sample solution in each well of the 96 -well microplate. After incubation at $37^{\circ} \mathrm{C}, 800 \mathrm{rpm}$ for $2 \mathrm{~h}$, the density of the strain was monitored by measuring the absorbance at $595 \mathrm{~nm}$. For determination of the $\beta$-galactosidase activity, $20 \mu \mathrm{L}$ of the bacteria culture and $210 \mu \mathrm{L}$ Z-buffer $(0.1$ mol sodium phosphate $\mathrm{pH} 7.4,10 \mathrm{mmol} \mathrm{KCl}, 10 \mu \mathrm{L}$ of $1 \mathrm{mg} \mathrm{mL}^{-1}$ sodium dodecyl sulfate, $1 \mathrm{mmol}$ $\mathrm{MgSO}_{4}$ containing $1 \mathrm{mg} \mathrm{L}^{-1}$ mercaptoethanol, and $5 \mu \mathrm{L}$ chloroform) were mixed. In the present study, a chromogenic substrate ortho-nitrophenyl- $\beta$-D-galactopyranoside (ONPG, Sigma-Aldrich, USA) was used to start the enzymatic reaction and $\mathrm{Na}_{2} \mathrm{CO}_{3}\left(1 \mathrm{~mol} \mathrm{~L}^{-1}\right)$ was used to terminate the reaction. Then, the absorbance at $420 \mathrm{~nm}$ and $570 \mathrm{~nm}$ was measured immediately. DMSO was used as the solvent control. Benzo a Pyrene (BaP) and 4-nitroquinoline-N-oxide (4-NQO) were taken as positive controls in the presence and absence of S9, respectively. The $\beta$-galactosidase activity (Unit) was calculated as follow:

$$
\beta-\text { galactosidase activity }(\text { Unit })=\frac{1000 \times(A 420-1.75 \times A 570)}{t \times v \times A 595}
$$

where $A 420, A 570, A 595$ are the optical densities at $420 \mathrm{~nm}, 570 \mathrm{~nm}$ and $595 \mathrm{~nm}, t$ is the incubation duration ( $\mathrm{min}$ ) of the enzyme reaction, and $v$ is the dilution rate of the bacterial suspension.

To avoid interference, the genotoxicology assessment was quantitatively expressed as induction ratio (IR): IR = Unit $t_{\text {sample }} /$ Unit $_{\text {solvent control. }}$ In general, the result is considered to be positive (+) if the IR value is above 1.5. The genotoxic potential for samples scored as a positive result can be expressed as the Toxic Equivalent Quantity (TEQ) values further. To express the direct and indirect genotoxic potential quantitatively, the following equations (4) and (5) are listed below:

$$
\begin{aligned}
& T E Q_{4-N Q O}\left(\mu \mathrm{g} \mathrm{L}^{-1}\right)=\text { Slope }_{\text {sample }} / \text { Slope }_{4-N Q O} \\
& T E Q_{B a P}\left(\mu g L^{-1}\right)=\text { Slope }_{\text {sample }} / \text { Slope }_{B a P}
\end{aligned}
$$

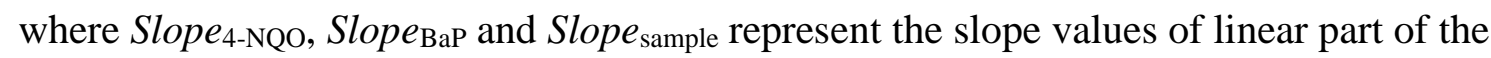
dose-response curves of the concentrated 4-NQO $(\mu \mathrm{g}), \mathrm{BaP}(\mu \mathrm{g})$ and samples $(\mathrm{L})$.

\subsection{Statistical analysis}

All data presented are expressed as mean \pm standard deviation (SD). The statistically 
significant effects of AMP exposure group and chlorination group compared with control group were evaluated using analysis of variance. Calculations were performed with GraphPad Prism ${ }^{\text {TM }} 6$ (GraphPad Software, San Diego, California, USA). According to Tukey's multiple comparisons tests, $P<0.05$ and $P<0.01$ were considered as significant and highly significant, respectively.

\section{RESULTS AND DISCUSSION}

\subsection{Effects on the growth of the $C$. vulgaris}

Fig.1 depicts the growth inhibition percentages of the $C$. vulgaris at different AMP concentrations. As shown in this figure, AMP had an inhibitory action on the growth of $C$. vulgaris. The growth inhibition percentage increased with the increase of AMP concentration, which exhibited a typical concentration-response curve. Over the 3-day exposure, the growth of the C. vulgaris was highly inhibited at $0.138 \mathrm{mmol} \mathrm{L}^{-1}$ AMP. This trend was evidently presented after 1 day's exposure (up to $37.3 \%$ inhibition). However, the inhibition percentage declined during the following two days of exposure. As a explanation for this decline, it seemed plausible that the $C$. vulgaris could partially degrade AMP and use it as nutrients instead of toxic substance (Wan et al., 2014; Yue et al., 2007). Additionally, the algae will generate the resistance under some injurious conditions in general. Crane et al. (2006) reported that algal growth could be controlled or modified by chemical means, and the resistance of alga to the chemical attack was determined. Gunnison and Alexander (1975) found that algae produced many antimicrobial agents, and it is quite possible that algal resistance is associated with toxic metabolites. Hence the decline as we tested might also be ascribed to the increased antimicrobial resistance of the $C$. vulgaris. The detailed mechanism needs to be further investigated.

The changes of the algal growth inhibition percentage at $0.009 \mathrm{mmol} \mathrm{L}^{-1}$ AMP concentration after AMP chlorination by different $\mathrm{Cl}_{2}$ doses were shown in Fig.2. Similar behavior was observed at AMP concentrations of $0.017,0.035,0.069,0.138 \mathrm{mmol} \mathrm{L}^{-1}$, and the data were given in the Supplementary Data. As shown in Fig.2, the growth of C. vulgaris at different molar ratios of AMP and chlorine (4:1, 1:1, 1:2 and 1:5) exhibited a couple of disparities: (i) when the molar ratios were 1:2 and 1:5, the inhibition effects on the growth of the $C$. vulgaris were greater after chlorination than the case of AMP exposure without chlorination; (ii) when the molar ratios were 4:1 and 1:1 (i.e., the chlroine dose decreased), 
the inhibition effects were weaker than the control case. It was reported that a wide range of disinfection by-products (DBPs) were attribute to differences in chlorine doses (Bond et al., 2014; Krasner et al., 2006; Krasner et al., 2009). The toxic DBPs of natural organic matter in the chlorinated water were the major factors causing algal growth inhibition (Liang et al., 2008). Liu and Zhang (2014) found the new halophenolic DBPs such as 5-halosalicylic acids were generally significantly more toxic to an autotrophic marine alga than the commonly known haloacetic acids. Several DBPs have been found to cause adverse toxicity in laboratory animals or aquatic organisms when given at high chlorine doses (Nieuwenhuijsen et al., 2000; Reif et al., 1996; Richardson, 2003). Thus, the formation of DBPs during AMP chlorination at different molar ratios of $\mathrm{AMP}$ and $\mathrm{Cl}_{2}$ might be helpful to explain these different inhibition effects in this study, and should be investigated in further study.

\subsection{Changes of SOD activity and MDA content}

In general, the rates of generation and scavenging of reactive oxygen species (ROS) in algal cells are kept balance. When the algae were under adverse conditions, such balance will be broken. The key antioxidant enzyme of SOD, which can protect algae from reactive oxygen damage, can be used to associate with ROS accumulation stress in algae cells. In this study, SOD activities of the $C$. vulgaris in the AMP exposure group, chlorination group and control group (mentioned in 2.2.4) were measured and presented in Fig. 3. In AMP exposure group, the SOD activities had a slightly stimulation at 0.009 and $0.017 \mathrm{mmol} \mathrm{L}^{-1}$ as compared with the control group. However, with the increase of AMP concentration, the activity of SOD was gradually inhibited. The results indicated that AMP had a low-dose stimulation and high-dose inhibition on the SOD activities of the C. vulgaris. Similar effects on enzyme activities by a variety of chemical substances were reported. Li et al. (2015) found that SOD activity in $S$. costatum cells significantly increased $(\mathrm{p}<0.05)$ with increasing nano- $\mathrm{TiO}_{2}$ concentration $\left(0 \sim 10 \mathrm{mg} \mathrm{L}{ }^{-1}\right)$ while decreased greatly $(\mathrm{p}<0.05)$ as the nano- $\mathrm{TiO}_{2}$ concentration exceeded $10 \mathrm{mg} \mathrm{L}^{-1}$. Hu et al. (2015) reported that the SOD activities of the protozoan Euglena gracilis were significantly induced $(\mathrm{p}<0.01)$ by graphene oxide at the concentrations from 0 to $2.5 \mathrm{mg} \mathrm{L}^{-1}$, but slightly decreased at $5.0 \mathrm{mg} \mathrm{L}^{-1}$ as compared with control. Another study demonstrated the activities of peroxidase (POD), which can prevent ROS from causing cellular damage like SOD, were stimulated at low test concentrations but inhibited at high concentrations during spiramycin exposure. Their study showed an 
$11 \% \sim 37 \%$ increase relative to the control at test concentrations of 50 100 ng L-1 and a relative decrease of $34 \% \sim 71 \%$ at $500 \mathrm{ng} \mathrm{L}^{-1} \sim 1 \mu \mathrm{g} \mathrm{L}-1$ (Liu et al., 2012).

The SOD activities of the $C$. vulgaris varied after AMP chlorination, as shown in Fig. 3. The data showed that SOD activity decreased with chlorine dose at each AMP concentration group. Additionally, compared with the control group, the SOD activity was stimulated at the relatively low chlorine dose while was inhibited at the relatively high chlorine dose. For instance, at the $0.138 \mathrm{mmol} \mathrm{L}^{-1} \mathrm{AMP}$ concentration group, the SOD activities were significantly induced $(\mathrm{p}<0.05)$ at AMP to chlorine molar ratios of 4:1 and 1:1, showing the $59.6 \%$ and 50.3\% increase compared with the control, respectively. Nevertheless, significant inhibition $(\mathrm{p}<0.05)$ was observed at AMP to chlorine molar ratios of 1:2 and 1:5, representing the $68.0 \%$ and $79.9 \%$ decrease, respectively. The possible reason for these results might be the DBPs formed at different AMP to chlorine molar ratios had distinct toxic impacts. It is likely to be that the DBPs formed at low chlorine dose could break the balance of generation and scavenging of ROS, resulting in stimulating of SOD activity. However, the DBPs formed at high chlorine dose might be resulted in the exceeded oxidative stress on the C. vulgaris and caused the inhibition of SOD activity.

MDA is a peroxidation product of cell membrane lipids and is commonly regarded as a momentous index to the oxidative damage status under environmental toxicants. Serious oxidative damage of toxic stress could result in the cell membrane lipid peroxidation and the MDA production. In the present study, the MDA levels of the C. vulgaris cells in AMP exposure group, chlorination group and control group were measured simultaneously. As illustrated in Fig. 4, in the AMP exposure group, the content of MDA increased with the AMP concentration, and significantly increased $(\mathrm{p}<0.05)$ at $0.138 \mathrm{mmol} \mathrm{L}^{-1}$ AMP up to 1.5-fold as compared with the control group. Similar results have been reported for different organisms in other bioassays. A previous study indicated that the gallic acid at high concentration led to the significant increase of the MDA content ( $<$ 0.05) in M. flos-aquae cells (Guo et al., 2015). Another study found that the content of MDA in M. aeruginosa cells increased with gramine concentration increasing, and up to 3.9 -fold relative to the controls at $8 \mathrm{mg} \mathrm{L}^{-1}(\mathrm{P}<0.001)$ (Hong et al., 2009).

After chlorination (i.e., the chlorination groups at different AMP concentrations), the content of MDA decreased slightly when the molar ratio of AMP to chlorine was 4:1, but increased when the ratios were 1:1, 1:2 and 1:5. For instance, at the $0.138 \mathrm{mmol} \mathrm{L}^{-1}$ of AMP, the content of MDA reduced only 0.1-fold at the AMP to chlorine molar ratio of 4:1, but 
enhanced significantly $(\mathrm{p}<0.05)$ with 1.1 -fold at the ratio of 1:5. As an explanation for the reason, it might also be resulted from the different DBPs formation at different molar ratios of AMP and chlorine. When the AMP to chlorine molar ratio was 4:1, the DBPs formed might not damage the membrane of the $C$. vulgaris cells. However, the DBPs formed at 1:1, 1:2 and 1:5 were most likely to accumulate the membrane lipid peroxidation and damage the membrane of the $C$. vulgaris cells resulting in the increase of MDA content.

\subsection{SOS/umu assay}

In this assay, the S. typhimurium TA1535/pSK1002 was exposed to AMP and to the corresponding chlorination treatment samples. Dose-response curves for the IR values were presented in Fig.5. The direct and indirect genotoxicity were represented in Fig.5(a) and Fig.5(b), respectively. Good dose-response relationships were interpreted from these two graphs. The slope values of the test samples increased with the increase of AMP to chlorine molar ratios, which indicated that the genotoxicity was greater at higher chlorine dose. In general, the test sample is considered to be positive $(+)$ when the IR value is more than 1.5 (Ye et al., 2014). When the molar ratios of AMP and chlorine were 1:1, 1:2 and 1:5, the IR values were above 1.5 , in other words, these three test samples were positive $(+)$. A positive genotoxicity signal in SOS/umu assay has to be considered as a possible relevant indicator for an existing human health risk (Hartmann et al., 1998). This implied that there was a health risk for human beings exposed to these DBPs formed during chlorination of drinking water containing AMP.

Furthermore, the genotoxic potentials of these positive samples are displayed as equivalents of the respective positive control substance in Table 1. In the absence of S9 (-S9), the direct DNA-damaging effect increased with the chlorine dose. The TEQ4-NQo values of the three positive samples above were ranged from the equivalent of 0.032 to $0.091 \mu \mathrm{g}$ of 4-NQO per liter, and the highest direct genotoxic potential was found at AMP to chlorine molar ratio of 1:5. Besides, the indirect DNA-damaging effects were also observed with metabolic activation by $\mathrm{S} 9(+\mathrm{S} 9)$. Similar to the aforementioned situation, it can be seen that the TEQ $\mathrm{BaP}$ values promoted successively from 13 to $25 \mu \mathrm{g} \mathrm{L}^{-1}$ with the chlorine dose increase. In brief, the higher chlorine dose can obviously enhance the genotoxicity. Previous study also indicated a positive evidence for the increasing toxicity in chlorination processes of antibiotics (Li et al., 2014). 
Matsushita et al. (2015) reported that iopamidol itself was not toxic to $V$. fischeri, however, chlorination of the iopamidol-containing solution induced both acute toxicity and mutagenicity resulting from its three DBPs. Miao et al. (2015) found that some oxidation by-products could lead to toxicity accumulation during AMP ozonation and were suggested to be more toxic than AMP. Hence, it is most likely that the DBPs formed after AMP chlorination result in the enhancement of the genotoxic potential. During AMP chlorination, the characteristic bands of aromatic ring gradually disappeared and the hydrogen atoms on the benzene ring may have been attacked and substituted by chlorine atoms (Cai et al., 2014; Rodil et al., 2012). The substitution of more halogen atoms on the benzene ring led to higher toxicity (Liu and Zhang, 2014). It might be speculated that the DBPs formed at high chlorine dose during AMP chlorination had more chlorine atoms substituted the halogen atoms on the benzene ring, so that they were more toxic than that formed at relatively low chlorine dose. Another hypothesis relates to the relative significance of oxidation and halogenation reactions by chlorine, which depend on the comparative concentrations of organic precursors and reaction sites within the chlorine dose (Bond et al., 2014). The detailed mechanism needs to be further investigated.

\section{CONCLUSIONS}

Acute toxicity and genotoxicity changed after the process of AMP chlorination. Algal toxicity assays confirmed that the growth and the SOD activity of the $C$. vulgaris were promoted at low chlorine dose (ie, the AMP to chlorine molar ratio of 4:1) but inhibited at high chlorine dose (ie, the AMP to chlorine molar ratio of 1:5). High concentrations of AMP and chlorine dose resulted in the content of MDA accumulated. Moreover, direct and indirect genotoxicity potentials were elevated after AMP clorine disinfection, indicating that the emerging DBPs deserve more attention. These toxicity data can help in prioritizing future research on drinking water DBPs. Although the potential eco-toxicities before and after AMP chlorination in ultrapure water were proposed, whether such results exist in real water systems merit further investigations.

\section{Acknowledgments}

This work is supported by the Fundamental Research Funds for the Central Universities (No.2015ZCQ-HJ-02), the Beijing Natural Science Foundation (No. 8152022) and National 
Science Foundation of China (No.51578066).

\section{References}

Bond, T., Huang, J., Graham, N.J., Templeton, M.R., 2014. Examining the interrelationship between DOC, bromide and chlorine dose on DBP formation in drinking water-A case study. Science of the Total Environment 470, 469-479.

Brausch, J.M., Rand, G.M., 2011. A review of personal care products in the aquatic environment: environmental concentrations and toxicity. Chemosphere 82, 1518-1532.

Cai, M.-Q., Wang, R., Feng, L., Zhang, L.-Q., 2015. Determination of selected pharmaceuticals in tap water and drinking water treatment plant by high-performance liquid chromatography-triple quadrupole mass spectrometer in Beijing, China. Environmental Science and Pollution Research 22, 1854-1867.

Cai, M.-Q., Zhang, L.-Q., Feng, L., 2014. Influencing factors and degradation behavior of propyphenazone and aminopyrine by free chlorine oxidation. Chemical Engineering Journal 244, 188-194.

Cleuvers, M., 2003. Aquatic ecotoxicity of pharmaceuticals including the assessment of combination effects. Toxicology letters 142, 185-194.

Crane, M., Watts, C., Boucard, T., 2006. Chronic aquatic environmental risks from exposure to human pharmaceuticals. Science of the Total Environment 367, 23-41.

Daughton, C.G., Ternes, T.A., 1999. Pharmaceuticals and personal care products in the environment: agents of subtle change? Environmental health perspectives 107, 907.

de Melo, E.D., Mounteer, A.H., de Souza Leão, L.H., Bahia, R.C.B., Campos, I.M.F., 2013. Toxicity identification evaluation of cosmetics industry wastewater. Journal of hazardous materials 244, 329-334.

Dodd, M.C., Shah, A.D., von Gunten, U., Huang, C.-H., 2005. Interactions of fluoroquinolone antibacterial agents with aqueous chlorine: reaction kinetics, mechanisms, and transformation pathways. Environmental science \& technology 39, 7065-7076.

Elkonin, L.A., Pakhomova, N.V., 2000. Influence of nitrogen and phosphorus on induction embryogenic callus of sorghum. Plant cell, tissue and organ culture 61, 115-123.

Federation, W.E., Association, A.P.H., 2005. Standard methods for the examination of water and wastewater. American Public Health Association (APHA): Washington, DC, USA.

GB/T15441, 1995. Water quality - determination of the acute toxicity - Luminescent bacteria test. , National Standard of China. 
Ge, F., Xu, Y., Zhu, R., Yu, F., Zhu, M., Wong, M., 2010. Joint action of binary mixtures of cetyltrimethyl ammonium chloride and aromatic hydrocarbons on Chlorella vulgaris. Ecotoxicology and environmental safety 73, 1689-1695.

Greskowiak, J., Prommer, H., Massmann, G., Nützmann, G., 2006. Modeling seasonal redox dynamics and the corresponding fate of the pharmaceutical residue phenazone during artificial recharge of groundwater. Environmental science \& technology 40, 6615-6621.

Guideline, I.H.T., 2011. Guidance on genotoxicity testing and data interpretation for pharmaceuticals intended for human use S2 (R1), International Conference on Harmonization of Technical Requirements for Registration of Pharmaceuticals for Human Use. ICH Expert Working Group, pp. 1-25.

Gunnison, D., Alexander, M., 1975. Resistance and susceptibility of algae to decomposition by natural microbial communities. Limnology and Oceanography 20, 64-70.

Guo, P., Liu, Y., Liu, C., 2015. Effects of chitosan, gallic acid, and algicide on the physiological and biochemical properties of Microcystis flos-aquae. Environmental Science and Pollution Research 22, 1-8.

Hartmann, A., Alder, A.C., Koller, T., Widmer, R.M., 1998. Identification of fluoroquinolone antibiotics as the main source of umuC genotoxicity in native hospital wastewater. Environmental Toxicology and Chemistry 17, 377-382.

Heberer, T., Reddersen, K., Mechlinski, A., 2002. From municipal sewage to drinking water: fate and removal of pharmaceutical residues in the aquatic environment in urban areas. Water Science \& Technology 46, 81-88.

Heberer, T., Verstraeten, I.M., Meyer, M.T., Mechlinski, A., Reddersen, K., 2011. Occurrence and fate of pharmaceuticals during bank filtration-preliminary results from investigations in Germany and the United States. Journal of Contemporary Water Research and Education 120, 2.

Hong, Y., Hu, H.-Y., Xie, X., Sakoda, A., Sagehashi, M., Li, F.-M., 2009. Gramine-induced growth inhibition, oxidative damage and antioxidant responses in freshwater cyanobacterium Microcystis aeruginosa. Aquatic Toxicology 91, 262-269.

Hu, C., Wang, Q., Zhao, H., Wang, L., Guo, S., Li, X., 2015. Ecotoxicological effects of graphene oxide on the protozoan Euglena gracilis. Chemosphere 128, 184-190.

ISO13829, I., 2002. Water quality-determination of the genotoxicity of water and waste water using the umu test. Geneva, Switzerland.

Jeličić, I., Ahel, M., 2003. Occurance of phenazone analgesics and caffeine in Croatian 
municipal wastewaters. Fresenius Environmental Bulletin 12, 46-50.

Kirkland, D., Henderson, L., Marzin, D., Müller, L., Parry, J., Speit, G., Tweats, D., Williams, G., 2005. Testing strategies in mutagenicity and genetic toxicology: an appraisal of the guidelines of the European Scientific Committee for Cosmetics and Non-Food Products for the evaluation of hair dyes. Mutation Research/Genetic Toxicology and Environmental Mutagenesis 588, 88-105.

Krasner, S.W., Weinberg, H.S., Richardson, S.D., Pastor, S.J., Chinn, R., Sclimenti, M.J., Onstad, G.D., Thruston, A.D., 2006. Occurrence of a new generation of disinfection byproducts. Environmental science \& technology 40, 7175-7185.

Krasner, S.W., Westerhoff, P., Chen, B., Rittmann, B.E., Amy, G., 2009. Occurrence of disinfection byproducts in United States wastewater treatment plant effluents. Environmental science \& technology $43,8320-8325$.

Li, F., Liang, Z., Zheng, X., Zhao, W., Wu, M., Wang, Z., 2015. Toxicity of nano-TiO 2 on algae and the site of reactive oxygen species production. Aquatic Toxicology 158, 1-13.

Li, M., Wei, D., Zhao, H., Du, Y., 2014. Genotoxicity of quinolones: Substituents contribution and transformation products QSAR evaluation using 2D and 3D models. Chemosphere 95, 220-226.

Liang, Y., Hong, H., Dong, L., Lan, C., Han, B., Wong, M., 2008. Sources and properties of natural organic matter (NOM) in water along the Dongjiang River (the source of Hong Kong's drinking water) and toxicological assay of its chlorination by-products. Archives of environmental contamination and toxicology 54, 597-605.

Liu, J., Zhang, X., 2014. Comparative toxicity of new halophenolic DBPs in chlorinated saline wastewater effluents against a marine alga: Halophenolic DBPs are generally more toxic than haloaliphatic ones. Water research $65,64-72$.

Liu, J.-L., Wong, M.-H., 2013. Pharmaceuticals and personal care products (PPCPs): a review on environmental contamination in China. Environment international 59, 208-224.

Liu, Y., Guan, Y., Gao, B., Yue, Q., 2012. Antioxidant responses and degradation of two antibiotic contaminants in Microcystis aeruginosa. Ecotoxicology and environmental safety 86, 23-30.

Matsushita, T., Kobayashi, N., Hashizuka, M., Sakuma, H., Kondo, T., Matsui, Y., Shirasaki, N., 2015. Changes in mutagenicity and acute toxicity of solutions of iodinated X-ray contrast media during chlorination. Chemosphere 135, 101-107.

Miao, H.-F., Zhu, X.-W., Xu, D.-Y., Lu, M.-F., Huang, Z.-X., Ren, H.-Y., Ruan, W.-Q., 2015. 
Transformation of aminopyrine during ozonation: Characteristics and pathways. Chemical Engineering Journal 279, 156-165.

Nieuwenhuijsen, M.J., Toledano, M.B., Eaton, N.E., Fawell, J., Elliott, P., 2000. Chlorination disinfection byproducts in water and their association with adverse reproductive outcomes: a review. Occupational and environmental medicine 57, 73-85.

Oda, Y., Nakamura, S.-i., Oki, I., Kato, T., Shinagawa, H., 1985. Evaluation of the new system (umu-test) for the detection of environmental mutagens and carcinogens. Mutation Research/Environmental Mutagenesis and Related Subjects 147, 219-229.

Oecd, 1994. OECD Guidelines for the Testing of Chemicals. Organization for Economic.

Quintana, J., Carpinterio, J., Rodríguez, I., 2007. Analysis fate and removal of pharmaceuticals in the water cycle. Elsevier, Amsterdam, pp. 20-47.

Reddersen, K., Heberer, T., Dünnbier, U., 2002. Identification and significance of phenazone drugs and their metabolites in ground-and drinking water. Chemosphere 49, 539-544.

Reif, J.S., Hatch, M.C., Bracken, M., Holmes, L.B., Schwetz, B.A., Singer, P.C., 1996. Reproductive and developmental effects of disinfection by-products in drinking water. Environmental health perspectives 104, 1056.

Reifferscheid, G., Heil, J., 1996. Validation of the SOS/umu test using test results of 486 chemicals and comparison with the Ames test and carcinogenicity data. Mutation Research/Genetic Toxicology 369, 129-145.

Richardson, S.D., 2003. Disinfection by-products and other emerging contaminants in drinking water. TrAC Trends in Analytical Chemistry 22, 666-684.

Rodil, R., Quintana, J.B., Cela, R., 2012. Transformation of phenazone-type drugs during chlorination. Water research 46, 2457-2468.

Sanderson, H., Johnson, D.J., Wilson, C.J., Brain, R.A., Solomon, K.R., 2003. Probabilistic hazard assessment of environmentally occurring pharmaceuticals toxicity to fish, daphnids and algae by ECOSAR screening. Toxicology Letters 144, 383-395.

Ternes, T.A., 1998. Occurrence of drugs in German sewage treatment plants and rivers. Water research 32, 3245-3260.

Ternes, T.A., Joss, A., Siegrist, H., 2004. Peer reviewed: scrutinizing pharmaceuticals and personal care products in wastewater treatment. Environmental Science \& Technology 38, 392A-399A.

Wan, J., Guo, P., Zhang, S., 2014. Response of the cyanobacterium Microcystis flos-aquae to levofloxacin. Environmental Science and Pollution Research 21, 3858-3865. 
Ye, Y., Weiwei, J., Na, L., Mei, M., Kaifeng, R., Zijian, W., 2014. Application of the SOS/umu test and high - content in vitro micronucleus test to determine genotoxicity and cytotoxicity of nine benzothiazoles. Journal of Applied Toxicology 34, 1400-1408.

Yue, X.-L., Yu, X.-Q., Liu, Y.-H., Dong, Y.-Y., 2007. Effect of bensulfuron-methyl on growth of Chlorella pyrenoidosa. Agricultural Sciences in China 6, 316-321.

Žegura, B., Heath, E., Černoša, A., Filipič, M., 2009. Combination of in vitro bioassays for the determination of cytotoxic and genotoxic potential of wastewater, surface water and drinking water samples. Chemosphere 75, 1453-1460. 


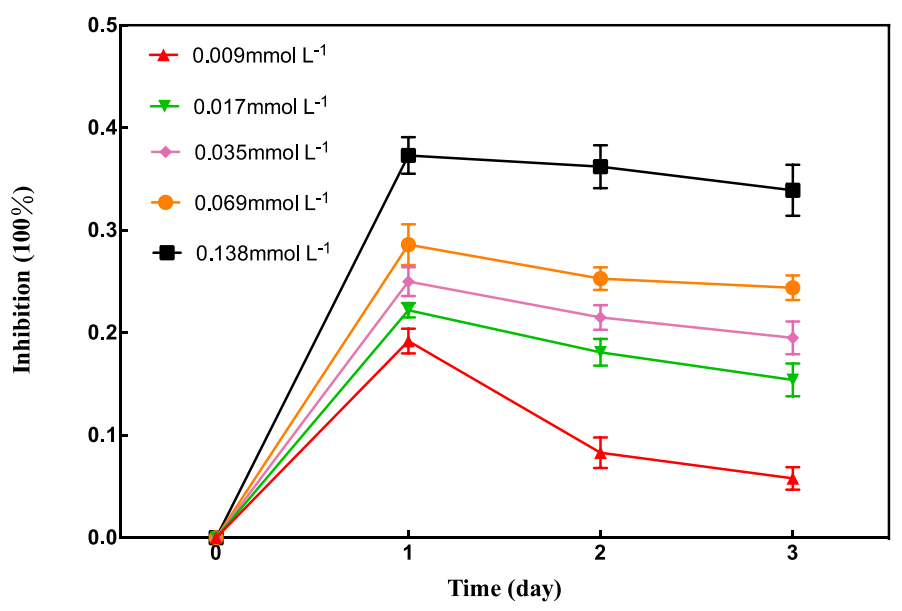

Fig.1 The growth inhibition percentages of the $C$. vulgaris at different AMP concentrations. 


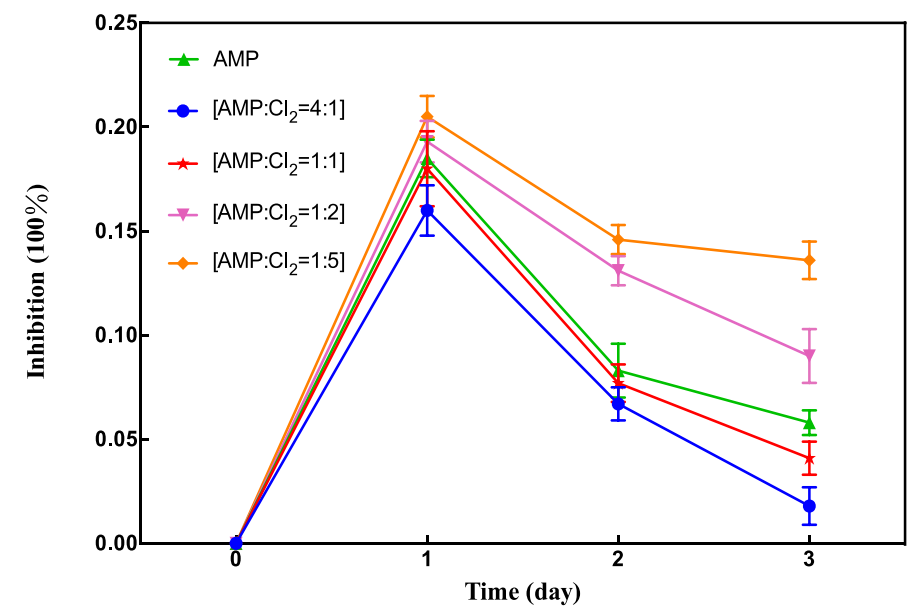

Fig. 2 The inhibition effects of AMP $\left(0.009 \mathrm{mmol} \mathrm{L}^{-1}\right)$ with/without chlorination on the growth of the $C$. vulgaris. 


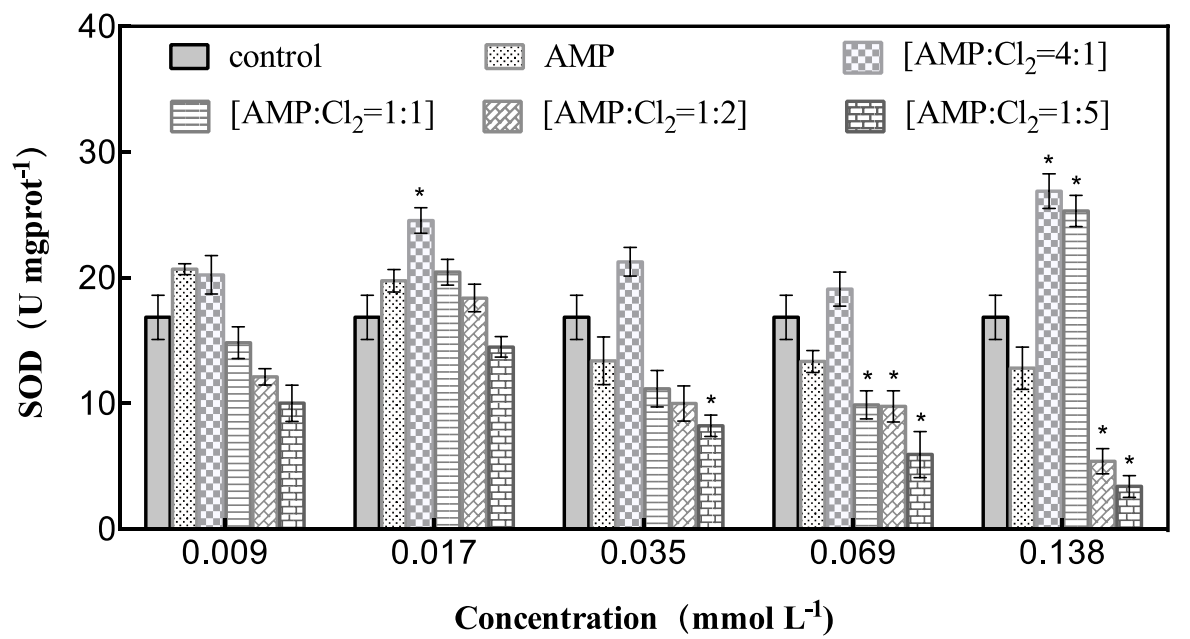

Fig. 3 The effects of AMP with/without chlorination on the SOD activity of the C. vulgaris. 


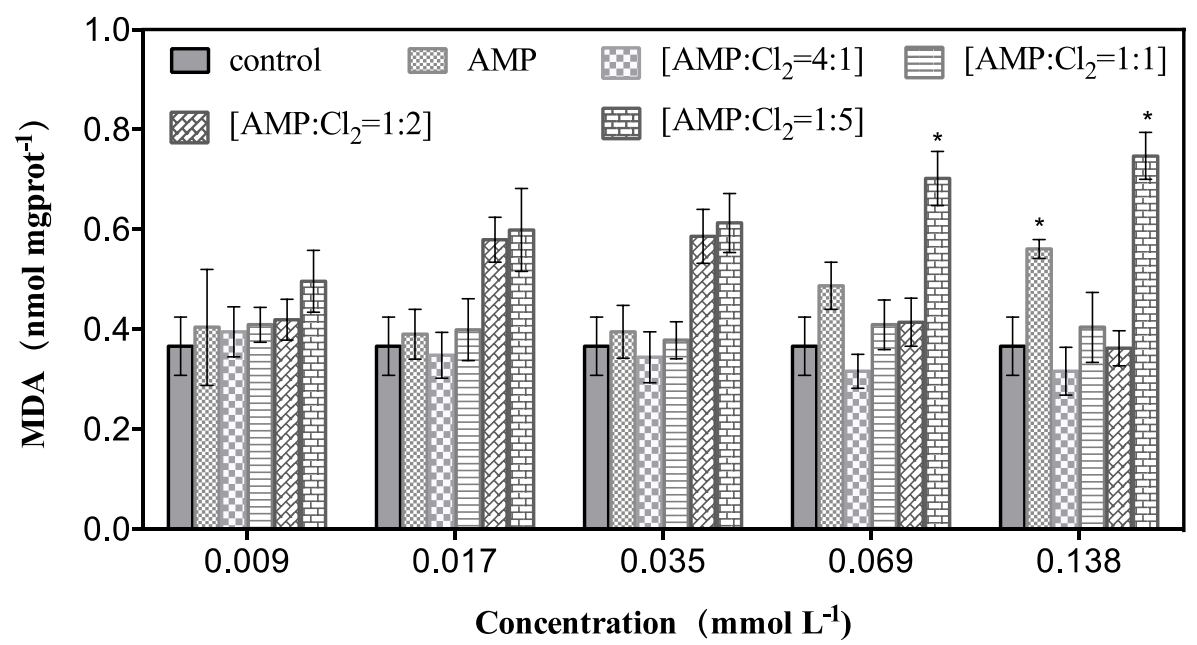

Fig. 4 The effects of AMP with/without chlorination on the content of MDA of the $C$. vulgaris. 


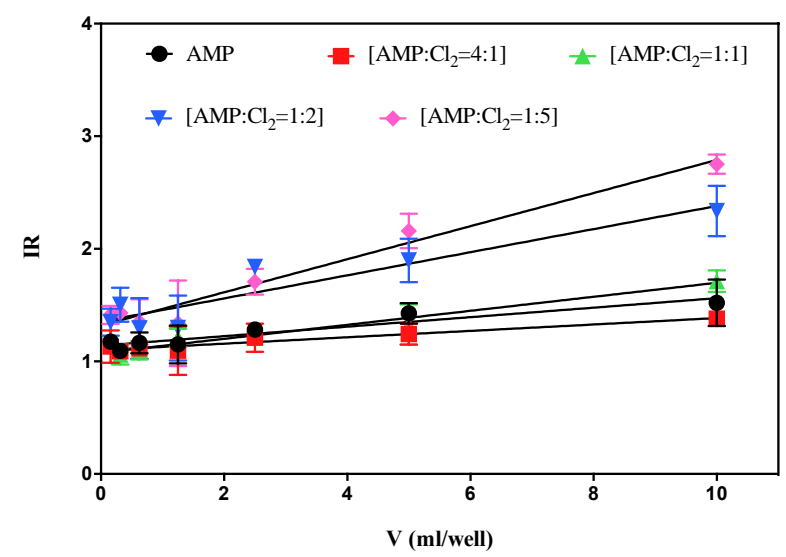

5(a)

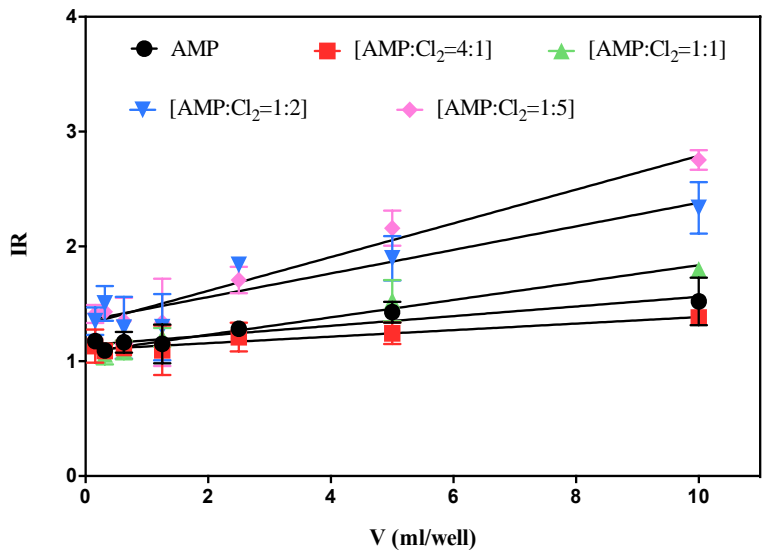

5(b)

Fig. 5 Dose-response curves for the induction ratio (IR) values when the S. typhimurium TA1535/pSK1002 was exposed to AMP and its corresponding chlorination treatment samples in the absence of $S 9$ (5(a)) and in the presence of $S 9(5(b))$. Each value represents the average of three replicate measurements \pm SD . 
Table 1. Summary of the TEQ4-NQO (-S9) and TEQ $\mathrm{BaP}_{4}(+\mathrm{S} 9)$ values of positive samples

\begin{tabular}{ccccc}
\hline \multirow{2}{*}{ Sample } & \multicolumn{2}{c}{ Slope $($ well $/ \mathrm{ml})$} & \multicolumn{2}{c}{ TEQ value $(\mu \mathrm{g} / \mathrm{L})$} \\
\cline { 2 - 5 } & $-\mathrm{S} 9$ & $+\mathrm{S} 9$ & $-\mathrm{S} 9$ & $+\mathrm{S} 9$ \\
\hline 4-NQO & 3171.897 & & & \\
& $($ well $/ \mu \mathrm{g})$ & & & \\
$\mathrm{BaP}$ & & 5.552 & & 13 \\
& & $($ well $/ \mu \mathrm{g})$ & & 19 \\
$\mathrm{AMP}: \mathrm{Cl}_{2}=1: 1$ & 0.094 & 0.063 & 0.032 & 25 \\
$\mathrm{AMP}: \mathrm{Cl}_{2}=1: 2$ & 0.119 & 0.107 & 0.041 & 0.091 \\
$\mathrm{AMP}: \mathrm{Cl}_{2}=1: 5$ & 0.266 & 0.138 & & \\
\hline
\end{tabular}

